\title{
A proposed voltage ride through compensators for improving power system performance
}

\author{
Hamed H. H. Aly ${ }^{1}$, Mahdi M. El-Arini' ${ }^{2}$, M. T. Youssef ${ }^{2}$ \\ ${ }^{1}$ Department of Electrical and Computer Engineering, Dalhousie University, Halifax, NS, B3H 4R2, Canada \\ ${ }^{2}$ Electrical Power \& Machines Engineering Department, Zagazig University, Faculty of Engineering, Zagazig, Egypt
}

Email address:

hamed.aly@dal.ca (Hamed H. H. Aly)

To cite this article:

Hamed H. H. Aly, Mahdi M. El-Arini, M. T. Youssef. A Proposed Voltage Ride Through Compensators for Improving Power System Performance, International Journal of Energy and Power Engineering. Vol. 2, No. 2, 2013, pp. 29-36.

doi: $10.11648 /$ j.ijepe.20130202.11

\begin{abstract}
Power quality is one of the most common problems now and in the near future especially after the increasing penetration of renewable energy in the power system grid. The abnormal operating conditions (such as heavy loading conditions, frequently starting of large induction motors and transmission system faults...) in electric system utility are considered as the main reasons of power quality problems. In this paper, the various main reasons of voltage sag problem are studied. The obtained results of the used simulation program (Electromagnetic Transient Programs ETAP and ATP) show the magnitude and duration of the voltage sag arising from the faults is more severe than that of the other causes, especially in the heavily loaded network. Also, three types of compensators (shunt, series and a combined of shunt and series (Unified Power Flow Controller (UPFC)) are addressed. The obtained results of hundred runs of the simulation program show the performance of the overall system before and after using different types of compensators. The proposed Unified Power Flow Controller (UPFC) gives better performance over the shunt and the series compensators. The most effective buses or lines (best location of compensators) also determined using the proposed system performance indices.
\end{abstract}

Keywords: Voltage sags, power quality, compensators, UPFC, ETAP, DDPMSG, DFIG

\section{Introduction}

Electrical power is considered as one of the most critical requirements for electrical power supply companies. DFIG (doubly fed induction generator) and DDPMSG (direct drive permanent magnet synchronous generator) are the most commonly used generators with wind and tidal current turbines. Different controllers are used for stabilization of DFIG and DDPMSG for both the grid side converter and the generator side converter for offshore wind turbines. Some of these controllers use the generator side converter controller to maintain the rotational speed of the generator at an optimal value, and minimize the core losses; and use the grid side converter controller to maintain the voltage of the DC-link, and control the output reactive power to a certain level. Other controllers use the generator side converter controller for controlling the output active power and reactive power, while using the grid side converter controller for controlling the DC-link voltage and the terminal voltage of the turbine system.

Power quality is one of the most common topics nowadays. During the fault condition most of generators connected with the wind and tidal turbines are switched off unless there is a ride through the compensator for compensating the required reactive power. Voltage sags are defined as a momentary decrease to between 0.1-0.9 p.u. in the root mean square (RMS) voltage magnitude at the power frequency for a duration from 0.5 cycles to one minute $[1,2]$. Its main reasons are large motor starting and electrical faults associated with heavily loading of cables and transmission systems [3].

Due to their small duration, voltage sags do not cause damage to motor or large equipments, although they cause some stresses on the insulation and disturbance to the operation. However, they can disrupt electronic equipments such as variable speed drives, Personal Computer's, etc., thus disrupting the overall operation $[4,5]$. As a special case for the renewable energy this will cause a switching off the generator. Voltage sags cause interruption to the production with the raw material loss in the 
production lines and damage to electronic boards [6]. This has been a major complaint by big customers like large industrial firms. It may be ranked as the second complaint of power quality after the harmonics. However, the extent of damage and business interruption due to the voltage sag is higher than harmonics. Most of the electronic equipments cannot be repaired locally and have to be imported from the manufacturer, which takes large time and high cost. The harmonics, damaging capacitors and cables, with a higher occurrence than voltage sags, are more easily to repair by substitution from the local market.

The problem is more severe in large industrial areas where cables and substation are highly loaded. In some cases where the voltage sag lasted to many cycles, damage to motors has been recorded. Lost information from Supervisory Controlled and Data Acquiescing systems has been also been noticed due to the disruption of remote modules.

In the following sections three compensators are proposed and their locations are determined using the proposed performance indices.

\section{Voltage SAGS}

Voltage sag is one the most important topics for dealing with the quality of the system. Equipments such as computers, process controllers, and power electronic devices are notorious for their sensitivity to power quality disturbances. DC devices and chillers control are also quite sensitive, and can trip on a reduction in the voltage as small as $10 \%$. Reduction of voltage sags may be done either by the end user or the utility. The interest and direct benefit of the end user is higher. Moreover, the solutions by the end user are far simpler and cheaper. This prompted the end users to take action. However, the utility is committed to provide high quality supply. The utility, also, suffers from false tripping of high sensitive protection equipments [7]. To prevent this localized, solutions should be taken. A feasible large scale solution will be more effective and, if less expensive could be the optimal solution of voltage sag problem.

There are several methods either on the utility or customer to reduce the number and severity of voltage sags and to reduce the sensitivity of equipment to voltage. Reduction of faults by monitoring, prediction and maintenance program is an effective step to minimize the number and severity of voltage sags. Fast fault clearing or isolation is recommended from this point of view. These procedures are the responsibility of the utility side.

End user [8] solutions mainly depend on stored energy such as Uninterruptible Power Supplies (UPS); MotorGenerator sets; Ferro resonant transformers; Magnetic synthesizers; Superconducting storage devices (SSD's), etc. These solutions are limited to small power and become very costly to cover large power. Some industrial sites have used Uninterruptible Power Supply (UPS) to supply the control of the machine while the power is supplied directly. This has been to reduce its size and cost while providing solution to minimize business interruption. Available in the market electronic (IGBT) sags protectors of small power up to $75 \mathrm{kVA}$, without batteries. These are cheaper than UPS but suffer from limited power and sag duration. Other solutions adopted by the end user include the use of reduced voltage starters for large motors. This, of course, is very helpful although it is not effective in eliminating outer voltage sags from neighboring consumers.

The use of stored energy on the utility side is very costly. The reserve capacity is not a solution unless it is injected on the bus suffering from voltage sag due to transmission capacities. The applications of UPFC to reduce the voltage sags in the power system is studied in [9-11].

Voltage ride through capability is an essential part in the wind and tidal current energy and most of the renewable energy systems. These energies depend on DDPMSG and DFIG for converting the mechanical energy to electrical energy. These generators need reactive power during the fault [12].

The proposed use of reactive compensation is more feasible from the economic point of view, easy to be installed. The compensator is connected in series with the most effective transmission line or more important buses. The best location of the compensator is based on the calculated value of the proposed performance index.

This work presents the use of compensators to reduce the voltage sags. Several types of compensators such as series, shunt and combined have been used. A comparison of the largest reduction is presented. The use of UPFC to reduce the voltage sag problem is proposed in this paper. A comparison between all tools and techniques to voltage sag is presented in this paper.

\section{Performance Index (PIV) and Per- formance Index Line (PIL)}

The performance of the voltage (PIV) has been used to find the most effective bus to install the compensator. This is done by injecting some of reactive power $(\Delta \mathrm{Q})$ at each bus and determining the Performance Index Voltage (PIV) in each case. The value of PIV is calculated as follows:

$$
P I V=\sum_{i=1}^{n B} W i\left(V_{b i}-V_{a i}\right)^{2 \mathrm{n}}
$$

$V_{b}=$ before injection, $V_{a}=$ after injection, $\mathrm{nB}=$ number of system buses, $\mathrm{n}$ is exponential and maybe $1,2,3, \ldots$ to remove the masking effect, $W i=$ weighting factor of busbar $\mathrm{i}$ and $\sum_{i=1}^{n B} W i=1$. 
The most important line is the line that has the largest ratio of the line power flow with respect to the total system demands. To find the most effective line to put series compensator we use performance index line (PIL) method or most important busbars.

$$
P I L=\sum_{i=1}^{n l}\left(P_{i} / P_{i \lim t}\right)^{2 \mathrm{n}}
$$

$\mathrm{P}_{\mathrm{i}}=$ power for line $\mathrm{I}$ except the faulted line, $\mathrm{P}_{\mathrm{ilim} t}$ $=$ power limit for line $\mathrm{i}$ except the faulted line, $\mathrm{nl}=$ number of system lines, $\mathrm{n}$ is exponential and maybe $1,2,3, \ldots$

The calculated values of PIV for the case study systems (4bus system and 14 bus system) show that the most effective bus would be busbar 3 for the 4-bus system, while the most effective bus for the 14-bus system is bus 14 .

\section{Unified Power Flow Controller (UPFC)}

The proposed Unified Power Flow Controller (UPFC) consists of two switching converters, which in the implementations considered are voltage source inverters using gate turn-off (GTO) thyristor valve, as illustrated in figure (1). These are operated from a common DC link provided by $\mathrm{AC}$ power converter in which the real power can flow in either direction between the AC terminal of the two inverters and each inverter can independently generate ( or absorb) reactive power at own $\mathrm{AC}$ output terminal.

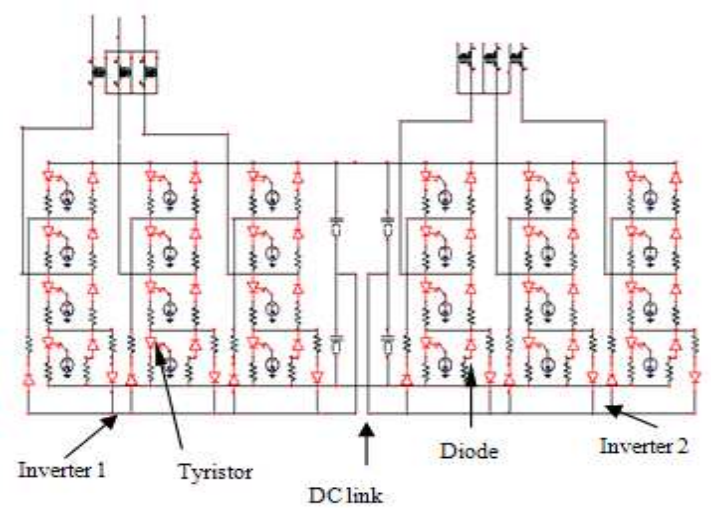

Fig. 1. Proposed UPFC construction

Inverter 2 provides the main function of the UPFC by injecting an AC voltage with controlled magnitude and phase angle, at the power frequency, in series with the line via insertion transformer. This injected voltage can be considered essentially as a synchronous AC voltage source. The transmission line current flows through this voltage source resulting in real and reactive power exchange between it and the $\mathrm{AC}$ system. The real power exchanged at the $\mathrm{AC}$ terminal(i.e., at the terminal of the insertion transformer) is converted by the inverter into dc power which appears at the DC link as positive or negative real power demand. The reactive power exchange at the AC terminal is generated internally by the inverter.

The basic function of the inverter 1 is to supply or absorb the real power demanded by Inverter 2 at the common DC link. This DC link power is converted back to $\mathrm{AC}$ and coupled to the transmission line via a shuntconnected transformer. Inverter 1 can also generate or absorb controllable reactive power, if it is desired, and thereby it can provide independent shunt reactive compensation for the line. It is important to note that whereas there is a closed "direct" path for real power negotiated by an action of the series voltage injected through Inverter 1 and 2 back to the line, the corresponding reactive power exchanged is supplied or absorbed locally by Inverter 2 and therefore it does not flow through the line. Thus, Inverter 1 can be operated at a unity power factor or be controlled to have a reactive power exchange with the line independently of the reactive power exchanged by Inverter 2 . This means that there is no continuous reactive power flow through the UPFC [7].

The proposed UPFC consists of twelve pulses (in four stages, each stage consists of one diode and one thyristor switched depending on pulsed signals)(two converters) in between a DC link through a capacitor, two transformer one connected series and the other connected shunt.

\section{Case Study Systems and Sags Analy- sis}

Simulations of faults and large motor starting have been done in 4-bus and 14-bus systems with different loading conditions. The system that suffered with the most severe voltage sags has been selected for the proposed solution analysis. The degree of voltage sag depends on the loading conditions and the distance between the bus and fault in interconnected multiple supply systems. Simulation has been done using the Electromagnetic Transient Program (ETAP). Figures 2 and 3 show the wiring diagram of 4-bus and 14-bus systems that have been investigated.

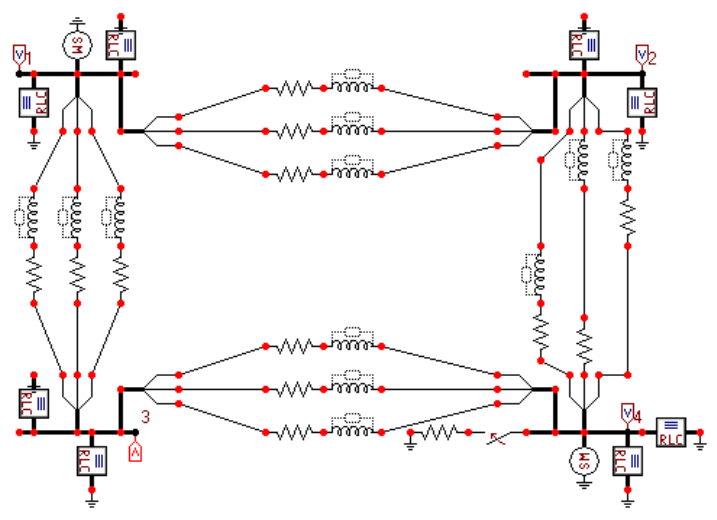

Fig 2. Wiring diagram of 4- Bus system 
The P.U. line data of 1000MVA, $230 \mathrm{kV}, 60 \mathrm{~Hz}$ base for 4-busbars and 14 busbars are given in tables(1,2). The light and heavy loading conditions P.U. data of the 4-bus system are shown in table (3.a, 3.b). Table (3.c) gives busbars data of 14 bus systems. The running of ETAP on the 4-busbars system under light and heavy loads for various types of fault are shown in tables ( $4,5 \& 6)$ to show the most affected bus by various faults simulations.

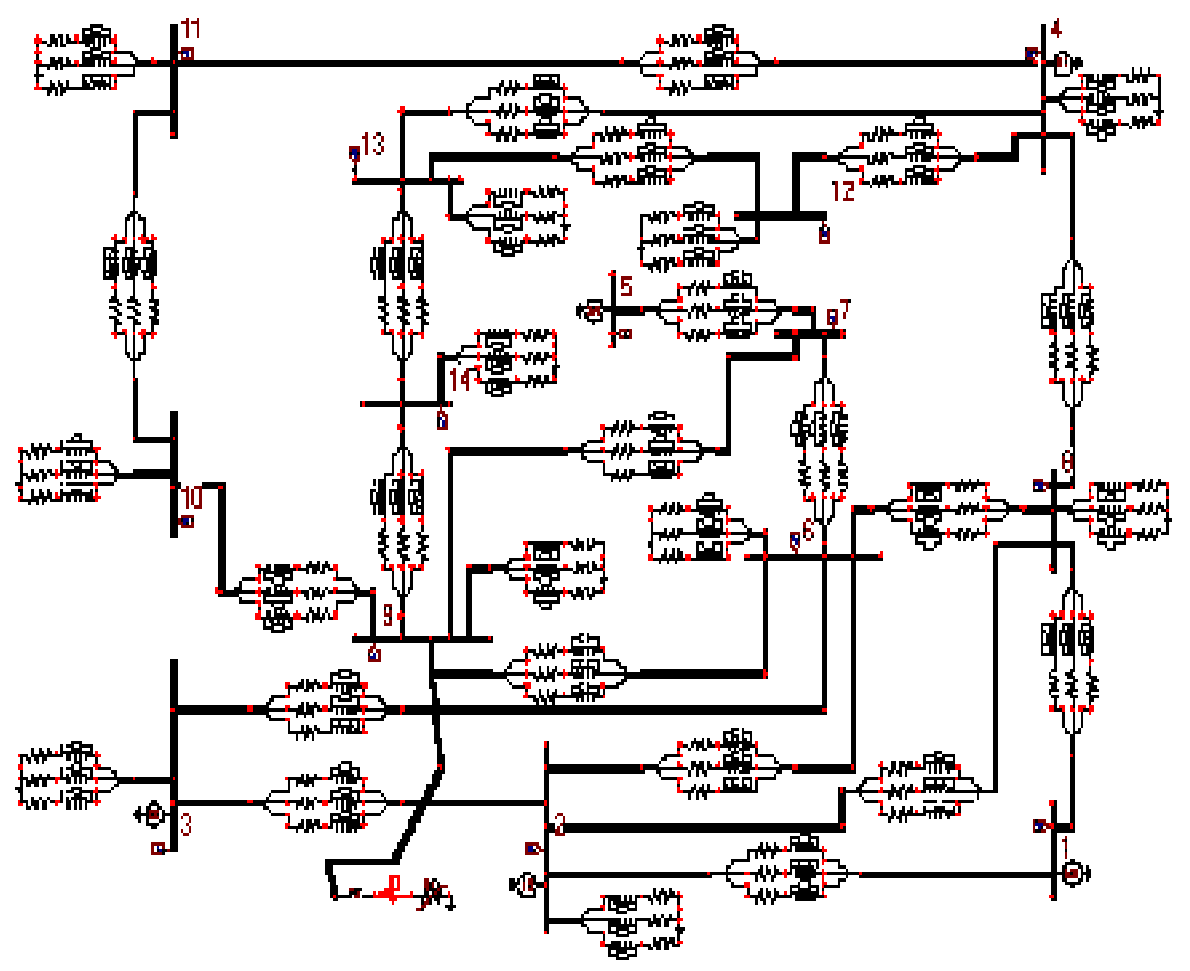

Fig 3. Wiring diagram of 14- Bus syst em

Table 1. Line data of 4 bus systems

\begin{tabular}{llll}
\hline Line code & P.U. Resistance & P.U. Reactance & P.U. Charing \\
\hline $1-2$ & 0.01008 & 0.0504 & 0.05125 \\
$1-3$ & 0.00744 & 0.03720 & 0.03875 \\
$2-4$ & 0.00744 & 0.03720 & 0.03875 \\
$3-4$ & 0.01272 & 0.06360 & 0.06375 \\
\hline
\end{tabular}

Table 2. Line data of 14 bus systems in P.U.

\begin{tabular}{lll}
\hline Line code & Resistance & Reactance \\
\hline $1-2$ & 0.03 & 0.05917 \\
$2-3$ & 0.03 & 0.19797 \\
$2-6$ & 0.03 & 0.17632 \\
$1-8$ & 0.02 & 0.22304 \\
$2-8$ & 0.02 & 0.17388 \\
$3-6$ & 0.02 & 0.17103 \\
$6-8$ & 0.02 & 0.04211 \\
$6-7$ & 0.01 & 0.20912 \\
$8-4$ & 0.01 & 0.25201 \\
$5-7$ & 0.01 & 0.17615 \\
$6-9$ & 0.01 & 0.55618 \\
$7-9$ & 0.01 & 0.1101 \\
$9-10$ & 0.02 & 0.08450 \\
$4-11$ & 0.03 & 0.19890 \\
$4-12$ & 0.04 & 0.25581 \\
$4-13$ & 0.03 & 0.13027 \\
$9-14$ & 0.02 & 0.27038 \\
$10-11$ & 0.02 & 0.19207 \\
$12-13$ & 0.01 & 0.19988 \\
$13-14$ & 0.03 & 0.34802 \\
\hline
\end{tabular}

Table 3.a Heavy load bus data of 4 bus systems

\begin{tabular}{lllllll}
\hline Bus code & Voltage & Angle & Pg & Qg & Pl & Ql \\
\hline 1 & 1 & 0 & 1.87 & 1.2425 & 0.5 & 0.3 \\
2 & 0.98 & -0.97 & 0 & 0 & 1.7 & 1.05 \\
3 & & & & & & \\
4 & 0.97 & -1.86 & 0 & 0 & 2 & 1.2399 \\
4 & 1.02 & 1.53 & 3.186 & 1.9 & 0.8 & 0.4958 \\
\hline
\end{tabular}

Table 3.b Light load bus data of 4 busbars system

\begin{tabular}{lllllll}
\hline Bus code & Voltage & Angle & Pg & Qg & PI & QI \\
\hline 1 & 1 & 0 & 11.35 & 6.1697 & 7.25 & 2.7 \\
2 & 0.891 & -12.4 & 0 & 0 & 3.9023 & 3.846 \\
3 & 0.913 & -10.2 & 0 & 0 & 3.9044 & 2.495 \\
4 & 1.02 & -13.9 & 3.186 & 8.8 & 3.7 & 3.5 \\
\hline
\end{tabular}


Table 3.c Heavy load bus data of 14 busbars system

\begin{tabular}{lllll}
\hline Bus code & Generation & MVAR & Load & MVAR \\
\hline 1 & MW & MW & 0.0 \\
2 & $\ldots$ & 15.00 & 28.1 & 25.00 \\
3 & 47.8 & 15.00 & 130.0 & 25.00 \\
4 & 34.00 & 15.00 & 15.3 & 7.5 \\
5 & 55.00 & 5.00 & 0.0 & 0.0 \\
6 & 55.80 & 0.0 & 64.2 & 15.00 \\
7 & 0.0 & 0.0 & 0.0 & 0.0 \\
8 & 0.0 & 0.0 & 9.70 & 5.0 \\
9 & 0.0 & 0.0 & 41.0 & 16.60 \\
10 & 0.0 & 0.0 & 14.20 & 5.80 \\
11 & 0.0 & 0.0 & 7.20 & 1.80 \\
12 & 0.0 & 0.0 & 8.90 & 6.10 \\
13 & 0.0 & 0.0 & 18.20 & 5.80 \\
14 & 0.0 & 0.0 & 21.00 & 5.00 \\
\hline
\end{tabular}

Table 4. Faulted voltages under light load conditions for 4 bus systems. Voltage is in KV.

\begin{tabular}{|c|c|c|c|c|c|c|c|c|c|c|c|c|c|}
\hline \multirow{2}{*}{ 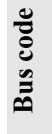 } & \multirow{2}{*}{ 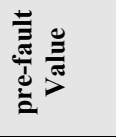 } & \multicolumn{3}{|c|}{ Line code 1-2 } & \multicolumn{3}{|c|}{ Line code $2-4$} & \multicolumn{3}{|c|}{ Line code 4-3 } & \multicolumn{3}{|c|}{ Line code 3-1 } \\
\hline & & L-G fault & L-L fault & $\begin{array}{l}\text { 3L-G } \\
\text { fault }\end{array}$ & L-G fault & L-L fault & $\begin{array}{l}\text { 3L-G } \\
\text { fault }\end{array}$ & L-G fault & L-L fault & $\begin{array}{l}\text { 3L-G } \\
\text { fault }\end{array}$ & L-G fault & $-L$ fault & $\begin{array}{l}3 \mathrm{~L}-\mathrm{G} \\
\text { fault }\end{array}$ \\
\hline \multirow[t]{3}{*}{1} & & 231.96 & 237.09 & & 226.71 & 234.46 & & 227.83 & 234.82 & & 233.47 & 236.65 & \\
\hline & 230.00 & 228.53 & 220.44 & 208.76 & 228.73 & 226.22 & 140.32 & 228.71 & 224.56 & 17.597 & 229.62 & 222.93 & 125.24 \\
\hline & & C 230.96 & 229.52 & & 231.05 & 229.62 & & 231.33 & 229.62 & & 230.17 & 229.41 & \\
\hline \multirow[t]{3}{*}{2} & & A 223.26 & 231.00 & & 215.85 & 232.70 & & 226.00 & 230.51 & & 226.73 & 231.00 & \\
\hline & 226.27 & В 224.96 & 221.55 & 82.28 & 225.62 & 217.39 & 5.924 & 225.71 & 221.88 & 197.90 & 225.52 & 225.46 & 168.98 \\
\hline & & C $\quad 227.00$ & 225.74 & & 226.93 & 225.98 & & 226.77 & 225.91 & & 226.79 & 221.78 & \\
\hline \multirow[t]{3}{*}{3} & & А 226.12 & 231.97 & & 223.82 & 229.46 & & 218.59 & 231.95 & & 212.34 & 230.57 & \\
\hline & 225.19 & В 224.57 & & 181.22 & 225.98 & 224.79 & 164.14 & 227.05 & 224.89 & 108.82 & 225.62 & 219.82 & 184.55 \\
\hline & & C $\quad 226.07$ & 220.07 & & 224.16 & 220.84 & & 224.03 & 214.74 & & 224.63 & 224.64 & \\
\hline \multirow[t]{3}{*}{4} & & А 228.99 & 233.40 & & 231.57 & 234.10 & & 231.27 & 233.71 & & 227.79 & 233.35 & \\
\hline & 230.00 & В 228.94 & 227.28 & 1450.0 & 229.54 & 225.70 & 215.84 & 229.51 & 226.23 & 219.38 & 229.02 & 227.28 & 205.70 \\
\hline & & C 230.75 & 229.61 & & 230.39 & 229.60 & & 230.32 & 229.68 & & 230.81 & 229.61 & \\
\hline
\end{tabular}

Table 5. Faulted voltages under heavy load conditions for 4 bus systems. Voltage is in KV.

\begin{tabular}{|c|c|c|c|c|c|c|c|c|c|c|c|c|c|c|}
\hline \multirow{2}{*}{ ङ } & \multirow{2}{*}{ 唼壱 } & \multicolumn{4}{|c|}{ Line code 1-2 } & \multicolumn{3}{|c|}{ Line code $2-4$} & \multicolumn{3}{|c|}{ Line code 4-3 } & \multicolumn{3}{|c|}{ Line code 3-1 } \\
\hline & & \multicolumn{2}{|c|}{ L-G fault } & \multirow{2}{*}{$\begin{array}{l}\text { L-L fault } \\
233.46\end{array}$} & $\begin{array}{l}\text { 3L-G } \\
\text { fault }\end{array}$ & \multicolumn{2}{|c|}{ L-G fault L-L fault 3} & $\begin{array}{l}\text { 3L-G } \\
\text { fault }\end{array}$ & \multicolumn{2}{|c|}{ L-G fault L-L fault } & $\begin{array}{l}\text { 3L-G } \\
\text { fault }\end{array}$ & \multicolumn{2}{|c|}{ L-G fault L-L fault } & $\begin{array}{l}\text { 3L-G } \\
\text { fault }\end{array}$ \\
\hline \multirow[t]{3}{*}{1} & & A & 234.14 & & & 222.98 & 232.35 & & 225.81 & 223.24 & & 236.33 & 234.03 & \\
\hline & 230.00 & B & 229.63 & 226.05 & 212.80 & 228.69 & 226.11 & 144.89 & 228.80 & 216.06 & 130.42 & .84 & 225.35 & 18.460 \\
\hline & & $\mathrm{C}$ & 230.15 & 229.31 & & 230.76 & 229.41 & & 230.48 & 218.41 & & 234.19 & 229.26 & \\
\hline \multirow[t]{3}{*}{2} & & A & \multicolumn{2}{|c|}{208.79224 .36} & & 197.61 & 224.39 & & 218.80 & 232.99 & & 227.90 & 222.58 & \\
\hline & \multirow[t]{2}{*}{229.30} & B & \multicolumn{2}{|c|}{218.27210 .76} & 8.403 & 219.21 & 210.76 & 6.095 & 218.77 & 227.93 & 55.552 & 228.64 & 215.78 & 84.763 \\
\hline & & $\mathrm{C}$ & 219.89 & 218.61 & & 219.56 & 218.61 & & 220.23 & 229.32 & & 230.64 & 218.58 & \\
\hline \multirow[t]{3}{*}{3} & & A & \multicolumn{2}{|c|}{221.93223 .38} & & 217.30 & 223.38 & & 208.85 & 223.73 & & 202.56 & 225.83 & \\
\hline & \multirow[t]{2}{*}{220.10} & B & \multicolumn{2}{|c|}{219.68216 .51} & 180.33 & 219.63 & 216.50 & 164.76 & 219.07 & 217.22 & 83.163 & 219.61 & 210.75 & 59.290 \\
\hline & & $\mathrm{C}$ & 221.73 & 219.37 & & 221.24 & 219.36 & & 220.62 & 219.35 & & 220.78 & 219.31 & \\
\hline \multirow[t]{3}{*}{4} & & A & \multirow{2}{*}{\multicolumn{2}{|c|}{$\begin{array}{l}227.25233 .43 \\
2291322626\end{array}$}} & & 234.08 & 233.27 & & 232.73 & 235.08 & & 220.49 & 232.79 & \\
\hline & \multirow[t]{2}{*}{230.00} & B & \multirow{2}{*}{229.13226 .26} & & 148.31 & 230.32 & 226.26 & 218.74 & 229.85 & 225.27 & 24.245 & 218.79 & 226.86 & 153.80 \\
\hline & & $\mathrm{C}$ & & 229.35 & & 229.81 & 229.35 & & 230.36 & 229.07 & & 220.03 & 229.35 & \\
\hline
\end{tabular}


Table 6. \% voltage sags for each type of fault under heavy load conditions for 4 bus systems. Voltage is in $\mathrm{KV}$.

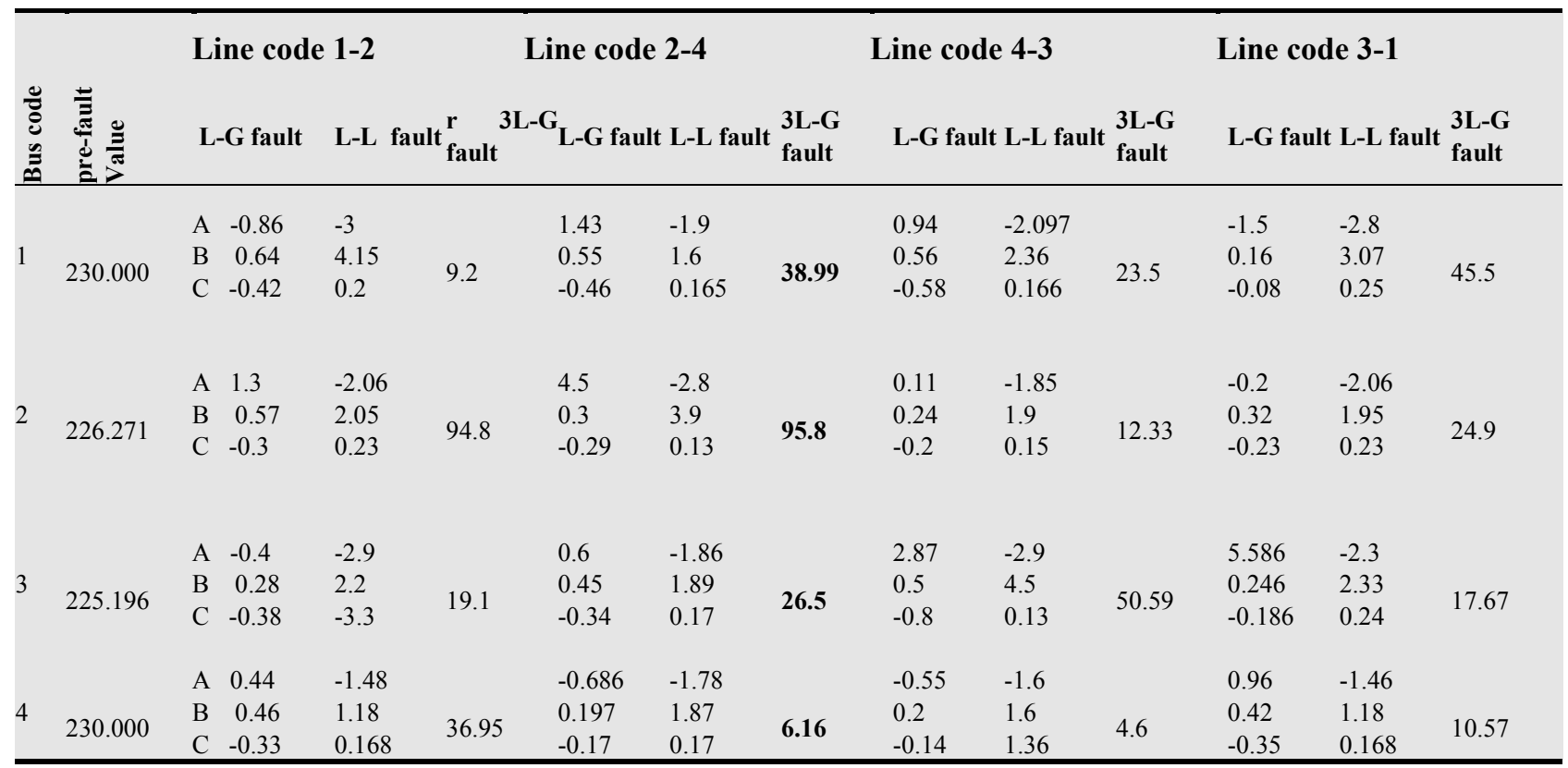

In this section we performed different types of fault for two loading conditions for 4 and 14 busbars systems. The obtained results from 4 busbars systems shows that the worst case is the $3 \mathrm{~L}-\mathrm{G}$ fault of the line (2-4) as shown in table (6) under heavy load conditions. For a 14 busbars system the $3 \mathrm{~L}-\mathrm{G}$ faults of all system lines are shown in table (7).

In the following section we try to use different voltage ride through capability to overcome this problem.

\section{Voltage Sags Reduction}

The proposed three types of voltage sags reduction (series compensator, shunt compensator and UPFC) are used with 4 busbars and 14 busbars systems.

Figure (4) shows the voltage for each busbar of 4 busbars system during a $3 \mathrm{~L}-\mathrm{G}$ fault in busbar number 3 without using any compensator. Figure (5) shows the voltage for each busbar of 4 busbars system during a 3L$\mathrm{G}$ fault in busbar number 3 after using shunt compensator. Figure (6) shows the voltage for each busbar of 4 busbars system during a 3L-G fault in busbar number 3 after using series compensator. Figure (7) shows the voltage for each busbar of 4 busbars system during a $3 \mathrm{~L}-\mathrm{G}$ fault in busbar number 3 after using UPFC. From which we concluded that using compensators reduced the percentage of the voltage sag.

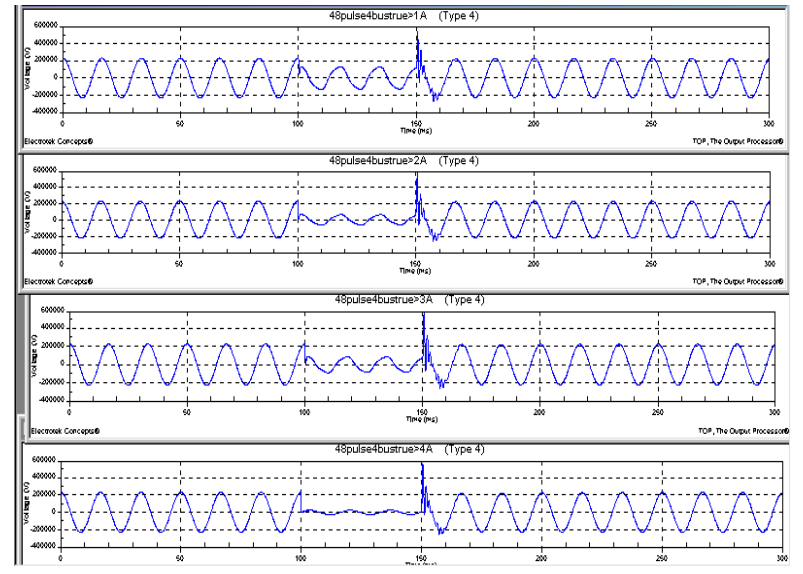

Fig 4. Voltage of 4-busbars system during $3 L-G$ fault.

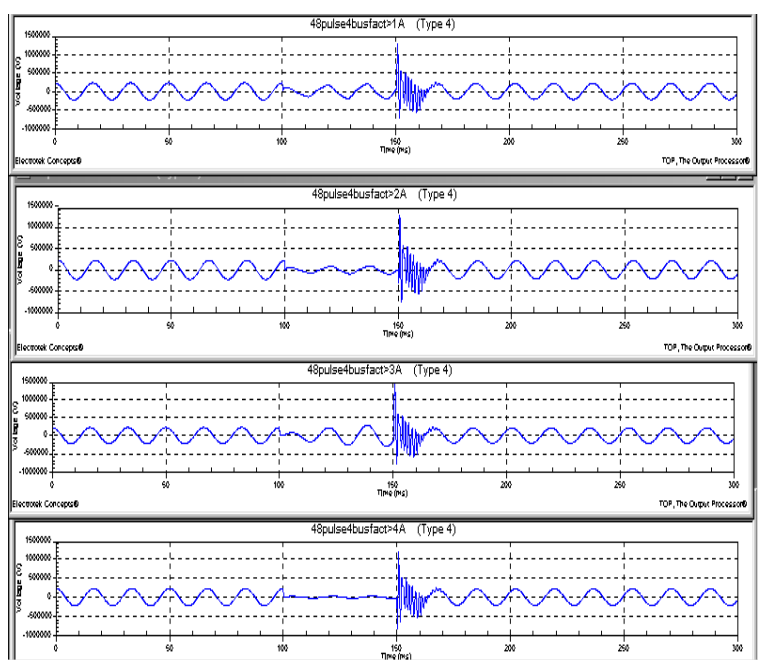

Fig 5. Voltage of 4-busbars system during $3 L-G$ fault using shunt compensator. 


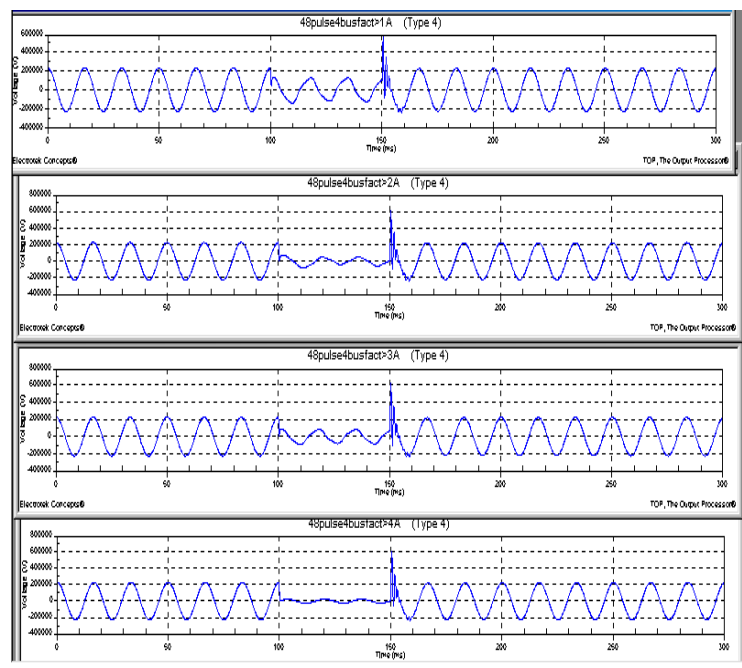

Fig 6. Voltage of 4-busbars system during $3 L-G$ fault using series compensator.

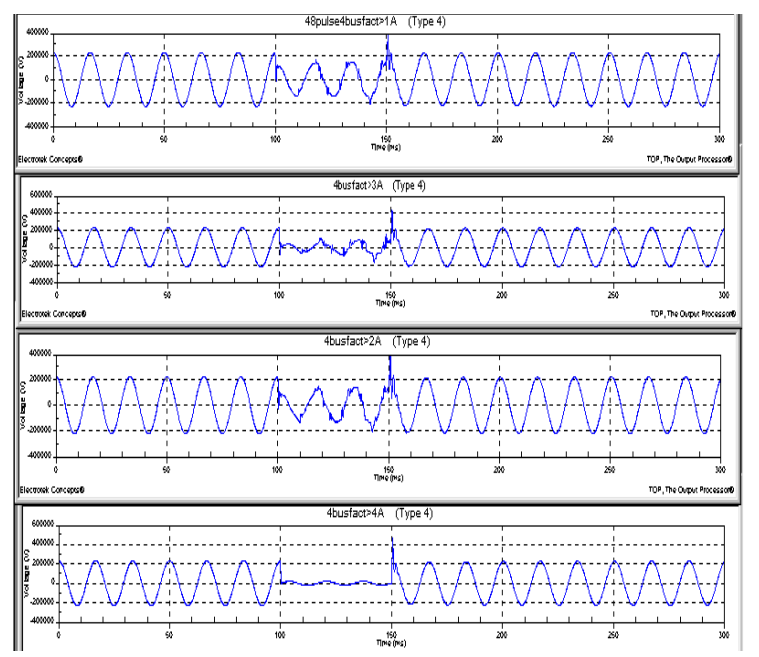

Fig 7. Voltage of 4-busbars system during $3 L-G$ fault using UPFC.

Tables $(8,9)$ show the percentage of reduction in the voltage sag for each type of compensator for both systems and at each busbar. Where: case 1 is \%Sag during fault without using Compensators, case 2 is \%Sag using series Compensators, case 3 is \%Sag using shunt Compensators and case 4 is \% Sag using UPFC. It may be noticed that the use of compensators in general is effective in the reduction of the voltage sag.

From table (8) we concluded that using any type of compensators is preferred as the percentage of the voltage sag is reduced after using a compensator. For example for busbar number 2 the percentage of the voltage was 72.92 before using any compensator and it turned to 70.07 after using a series compensator and then to 63.5 after using a shunt compensator and finally turned to 36.7 after using UPFC. The overall results shows that using $\mathrm{UPFC}$ is the best way for the voltage sag reduction.

Also from table (9) we concluded that using any type of compensators is preferred as the percentage of a voltage sag is reduced after using a compensator. For exam- ple for busbar number 8 the percentage of the voltage was 27.9 before using any compensator and it turned to 26.67 after using a series compensator and then to 26.7 after using a shunt compensator and finally turned to 24.9 after using UPFC. Overall results shows that using UPFC is the best way for the voltage sag reduction.

Compensators are present now in many networks and with small control system can be used effectively for such purpose. The detection and control time is very small due to the use of electronic or microprocessor transducers and thyristors to insert the compensator in the system. This makes it more effective as the voltage sag does not exceed a few cycles. The UPFC is the most effective type of compensators.

Table 7.\% Voltage sags on each bus due to $3 L-G$ fault on each line for 14 busburs system.

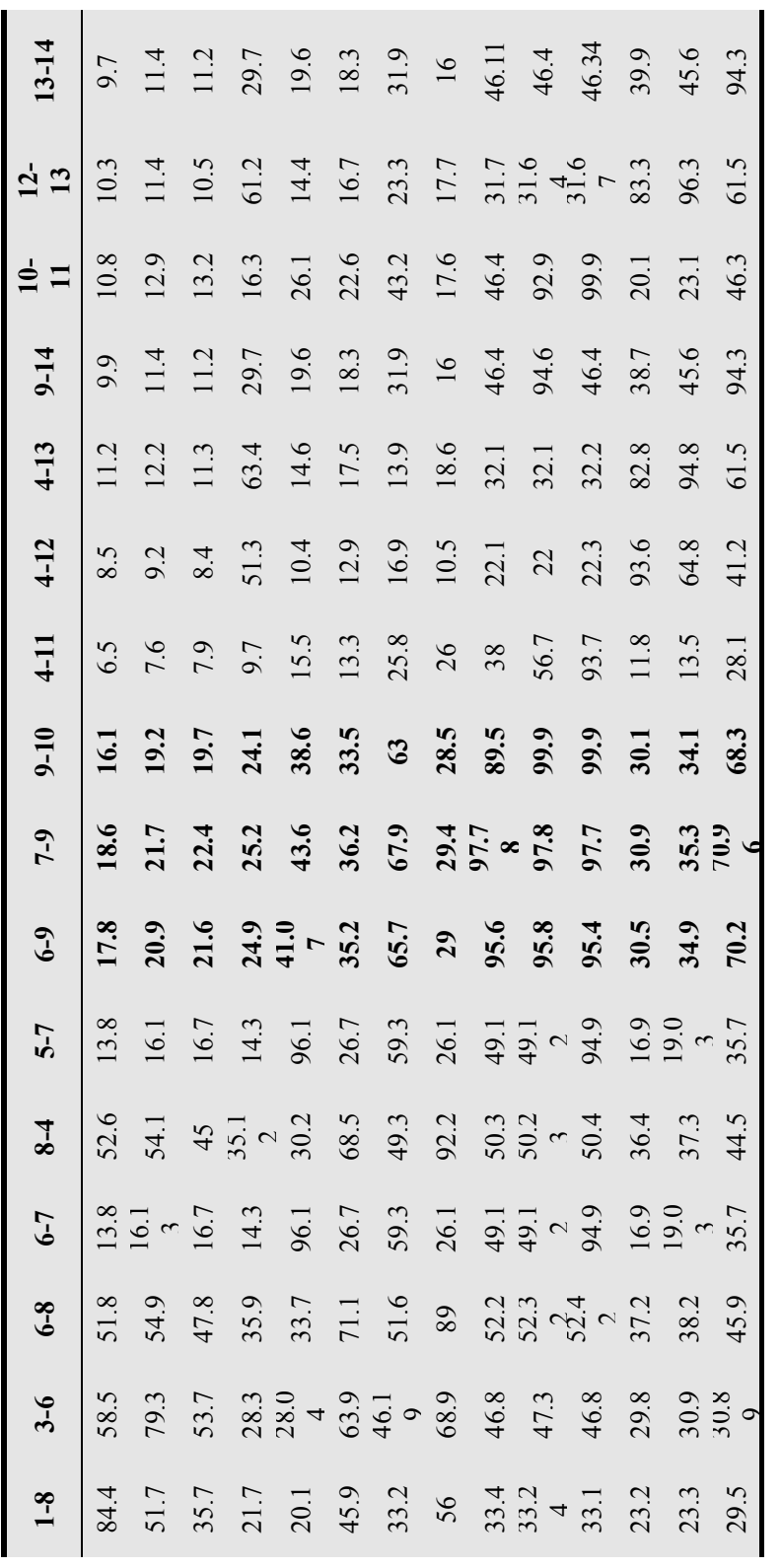




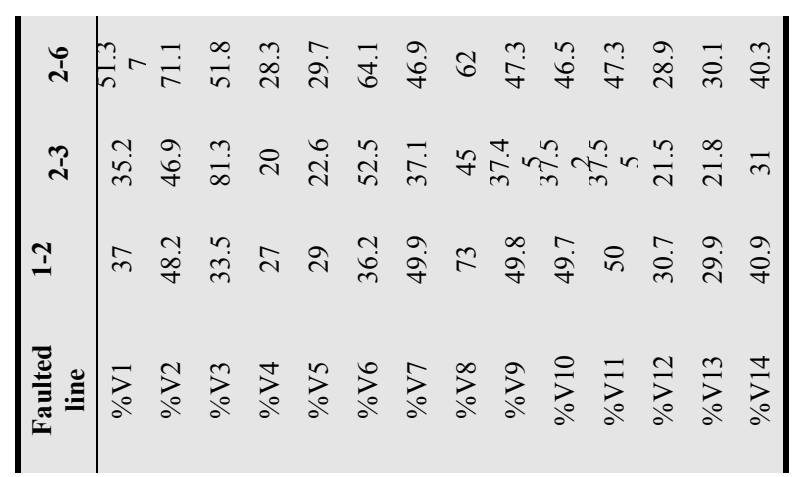

Table 8. Comparison between series, shunt and UPFC Compensators.

\begin{tabular}{lllll}
\hline Bus Code & Case 1 & Case 2 & Case 3 & Case 4 \\
\hline 1 & 44.05 & 45.16 & 26.1 & 27.7 \\
2 & 72.92 & 70.07 & 63.5 & 36.7 \\
3 & 63.36 & 63.4 & 60.1 & 52.9 \\
4 & 88.7 & 88.04 & 87.6 & 90.2 \\
\hline
\end{tabular}

Table 9. Comparison between series, shunt and UPFC Compensators Using $C=6.4 * 4 \mu f(3 * 8.53)$ Where: $\%$ Sag $=(230000$ - Voltage during Fault)/230000

\begin{tabular}{lllll}
\hline Bus Code & Case 1 & Case 2 & Case 3 & Case 4 \\
\hline 1 & 17.16 & 16.1 & 16.5 & 14.3 \\
2 & 20.1 & 19.02 & 19.3 & 17.4 \\
3 & 20.6 & 19.5 & 19.9 & 19.01 \\
4 & 23.2 & 21.7 & 18.15 & 14.7 \\
5 & 40.2 & 37.2 & 37.02 & 37.07 \\
6 & 35.9 & 34.7 & 34.9 & 33.6 \\
7 & 66.4 & 63.2 & 63.04 & 62.5 \\
8 & 27.9 & 26.67 & 26.7 & 24.9 \\
9 & 98.11 & 90.28 & 90.07 & 90.25 \\
10 & 98.09 & 90.5 & 89.8 & 90.1 \\
11 & 98.1 & 90.5 & 89.83 & 90.2 \\
12 & 30.3 & 28.9 & 24.7 & 22.14 \\
13 & 35.08 & 33.7 & 29.09 & 26.7 \\
14 & 71.7 & 68.9 & 60.7 & 61.1 \\
\hline
\end{tabular}

\section{Conclusion}

The increasing penetration of renewable energy into the electrical power system grid makes the power quality studies very important topic nowadays and in the near future. Voltage sags are one of the most important issues in the power system quality. This paper proposed two different performance indices for determining the best location of the voltage ride through compensator during the voltage sags. The location of the compensator by the PIV method has been proved to be correct by multiple tests done on various buses. This paper investigates a utility side solution for the problem of voltage sags. The end user solution suffers from small power and eliminates only downstream effects. The use of voltage ride through compensator is very important especially for the renewable energy. Three types of compensators are proposed and tested for improving the power system quality. The results show the use of the proposed UPFC is more beneficial compared to the shunt or the series.

\section{References}

[1] Roger C. Dugan, M.F. McGranaghan and H. W. Beaty "Electrical power systems quality" McGrawHill,USA, 1996

[2] Erich W. Gunther Electrotek Concepts, Inc., Harshad Mehata Electric Power Research Institute" A Survey of distribution system power quality preliminary results" IEEE Transaction Power Delivery, 1995, Vol.10, No. 1 ,p.p 322-329.

[3] M.F. McGranaghan, D.R. Mueller and M.J. Samotyj, "Voltage Sags in Industrial Systems", IEEE Transactions on Industry Applications, Vol. 29, No. 2, March/April 1993.

[4] Jose Luis Duran-Gome, Student Member, IEEE, Prasad N. Enjeti, Senior Member, IEEE, and Byeong Ok Woo " Effect of Voltage Sags on Adjustable-Speed Drives: A critical Evaluation and an Approach to Improve Performance" ", IEEE Transactions on Industry Applications, Vol. 35, No. 6, November/December 1999.

[5] Perm P. Khhera, Member, IEEE, and Kevin C. Dickey, Member, IEEE "Analysis and mitigation of voltage disturbances at an industrial customer's corporate campus" IEEE. Transaction on industry applications, Vol. 34, No. 5, September/October 1998.

[6] FABIO Tosato and Stefano Quaia " Reducing Voltage Sag Through Fault Current Limitation", IEEE Transactions on Power Delivery, Vol. 16, No. 1, January 2001.

[7] William E. Brumsickle, Member, IEEE, Robert S. Schneider, Member, IEEE, Glen A. Luckjiff, Deepak M. Divan, Fellow, IEEE, and Mark F. McGranaghan, Member, IEEE" Dynamic sag correctors: cost effective industrial power line conditioning" IEEE. Transaction on industry applications, Vol. 37, No. 1, Jan./Feb. 2001

[8] J. Lamoree, D. Mueller, P. Vinett, W. Jones and M. Samotyj, "Voltage Sag Analysis Case Studies", IEEE Transactions on Industry Applications, Vol. 30, No. 4, July/August 1994.

[9] X. P. Zhang "Modelling of the interline power flow controller and the generalized unified power flow controller in Newton power flow", IEEE Proceding Generation Distriution, Vol. 150, No. 3, May 2003.

[10] Gyugyi L.,Shanuder C. D. ,Willims S. L. , Rietman T. R. ,Torgrerson D. R. and Edris A. "The Unified Power Flow Controller a new approach to power transmission control" IEEE Trans. Power Delivery, 1995.

[11] Mahdi M. El-Arini, Youssef M.T., and Hamed H. Hendawy, "Voltage Sag Analysis and its Reduction to Improve Power System Performance," $11^{\text {th }}$ IEEE International Medial East Conference (MEPCON), El-Minia, Egypt 2006.

[12] Hamed H. H. Aly, M. E. El-Hawary, "The Current Status of Wind and Tidal in-Stream Electric Energy Resources, American Journal of Electrical Power and Energy Systems". Vol. 2, No. 2, 2013, pp. 23-40. 